\title{
Effects of biosurfactants on surface properties of hematite
}

\author{
Agnieszka Szymanska $\cdot$ Zygmunt Sadowski
}

Published online: 3 August 2010

(c) The Author(s) 2010. This article is published with open access at Springerlink.com

\begin{abstract}
Application of microorganisms as surface modifiers has focused our attention in recent times. The adsorption of biosurfactants can be a way for the solid surface modification. In the present investigation rhamnolipids produced by Pseudomonas aerugiosa were used to make the hematite surface modification. Experiments were carried out with pure mineral hematite. In this paper, the influence of biosurfactant addition on both the stability and the flotability of hematite suspensions has been studied in detail. The stability experiments were conducted using Turbiscan LA $b$ apparatus, at constant $\mathrm{pH}$ conditions and mineral amount. The flotation experiments were carried out using Hallimond tube. The adsorption isotherms of biosurfactant onto the hematite particles were also determined. The experiments were carried out with broth and pure rhamnolipid. The results of those experiments were compared and discussed.
\end{abstract}

Keywords Biosurfactants · Rhamnolipid · Adsorption · Sedimentation $\cdot$ Flotation $\cdot$ Hematite

\section{Introduction}

Microorganisms are capable of generating biosurfactans which find use in the mineral surface modification. The utility of extracellular metabolic products of both bacteria and yeast in selective flotation and flocculation has been reported (Botero et al. 2008). Biosurfactants are biological surfaceactive compounds released by microorganisms that can have

A. Szymanska $\cdot$ Z. Sadowski $(\bowtie)$

Department of Chemical Engineering, Faculty of Chemistry,

Wroclaw University of Technology, Wybrzeze Wyspianskiego 27,

50-370 Wroclaw, Poland

e-mail: zygmunt.sadowski@pwr.wroc.pl some influence on the solid/water interfaces. These compounds manifest the properties similar to the well-known synthetic surfactant family but they are easily for environmental bioremediation.

Yeast and bacteria can produce biosurfactants from various substrates including sugar, oils, alkanes and organic wastes. Most of biosurfactants are either anionic or neutral, while only a few with amine groups are cationic (Mukherjee et al. 2006). Biosurfactans include a wide variety of surface active compounds such as: (i) glycolipids, (ii) lipoproteinslipopeptides, (iii) phospholipids, (iv) lipopolysaccharides.

Growth of bacteria and yeast in the presence of various minerals results in the adsorption of extracellular biosurfactants and other metabolic products on the mineral surface. In order to characterize the behavior of biosurfactant, the surface excess and the rate of adsorption should be investigated.

Biosurfactants have advantages over their chemical counterparts in biodegradability and effectiveness at extreme temperature or $\mathrm{pH}$ and in having lower toxicity (Banat et al. 2000).

Biosurfactant molecules reduce surface tension, effect on the critical micelle concentration (CMC) and interfacial tension (IFT) in both aqueous solutions and hydrocarbon mixtures (Das and Mukherjee 2005).

Pseudomonas aeruginosa shows an overproduction of rhamnolipid biosurfactant when the culture reaches the stationary growth phase due to limitation of the nitrogen source. Four different rhamnolipid homologues, secreted by this strain, have been identified and characterized. These homologues contain one or two molecules of rhamnose as the carbohydrate component and one or two residues of $\beta$-hydroxydecanoic acid as the lipid moiety (Sim et al. 1997).

Adsorption of surfactants and biopolymers (proteins) at the solid-liquid interfaces is used widely to modify sur- 
face properties of solids in a variety of industrial processes such as flotation, flocculation and oil recovery (Microbial Enhanced Oil Recovery-MEOR) (Bordoloi and Konwar 2008). The role of fractionated proteins from Paenibacillus polymyxa in selective mineral separation was demonstrated (Patra and Natarajan 2008).

This study aimed to provide some experimental bases for application of biosurfactants in the mineral surface modification. Particularly, we describe the adsorption of pure biosurfactant and from the crude fermentation medium (broth) on the hematite particle surface. Additionally, the stability and the floatability of hematite suspension after establishing a contact with pure rhamnolipid and the crude broth were investigated.

\section{Materials and methods}

\subsection{Mineral preparation}

The sample of hematite used in this study was purchased by Ward's Natural Science, Rochester, NY (USA).

Three particle classes of mineral were obtained: $-40 \mu \mathrm{m}$, $+40-125 \mu \mathrm{m}$ and $+125-300 \mu \mathrm{m}$. The specific surface area of the samples measured with the FlowSorb II 2300, according to the BET method, was: $1.748 \pm 0.012 \mathrm{~m}^{2} / \mathrm{g}$, $0.2135 \pm 0.011 \mathrm{~m}^{2} / \mathrm{g}$ and $0.1524 \pm 0.0188 \mathrm{~m}^{2} / \mathrm{g}$ respectively. As a gas the mixture of helium and nitrogen was used.

\subsection{Microorganism and culture media}

The bacterial strain used in experiments was Pseudomonas aeruginosa. Microorganisms were isolated from soil. The soil samples were collected from gas station soil. Bacteria were grown in liquid medium consisting of $2.0 \%$ mannitol, $0.4 \% \mathrm{NH}_{4} \mathrm{NO}_{3}, 0.4 \% \quad \mathrm{KH}_{2} \mathrm{PO}_{4}, 1.43 \% \mathrm{Na}_{2} \mathrm{HPO}_{4} \cdot 7 \mathrm{H}_{2} \mathrm{O}$, $0.0096 \% \mathrm{MgSO}_{4}, 0.0010 \% \mathrm{FeSO}_{4} \cdot 7 \mathrm{H}_{2} \mathrm{O}$, a pinch of $\mathrm{CaCl}_{2}$ and EDTA. These chemicals were used as received without further purification. The strain was cultured in $250 \mathrm{ml}$ Erlenmeyer flasks. The cultures were incubated in a rotary shaker at the room temperature. The cell growth was monitored by measuring the optical density at $600 \mathrm{~nm}\left(\mathrm{OD}_{600}\right)$. After $72 \mathrm{~h}$ culture was centrifuged and the supernatant was used for further experiments as a broth. The concentration of biosurfactants in a broth was estimated by determining the rhamnose concentration (George and Jayachandran 2009).

\subsection{L-rhamnose analysis}

The rhamnolipid amount was determined indirectly by measuring amount of rhamnose in broth solutions (Rahman et al. 2002). The standard curve for rhamnose was determined. Three reagents were used: 1 . Sulfuric acid: concentrated
(95\%) sulfuric acid $(90 \mathrm{ml})$ was added to $15 \mathrm{ml}$ of distilled water cooled in ice, 2 . Thioglycolic acid: $0.1 \mathrm{ml}$ of thioglycolic acid was diluted to $3 \mathrm{ml}$ with water just before use and rhamnose standard: $4 \mathrm{mg}$ of L-rhamnose was dissolved in $100 \mathrm{ml}$ of water $(40 \mu \mathrm{g} / \mathrm{ml})$ just before use. Aliquots of the standard of L-rhamnose solution $(0$ to $1.0 \mathrm{ml}$ by $0.1 \mathrm{in}$ crements) were transferred by pipette to test tubes, and the volume was brought to $1 \mathrm{ml}$ with water. Sulfuric acid solution $(4.5 \mathrm{ml})$ was added. The solution was then heated in boiling water for $10 \mathrm{~min}$. The tubes were cooled in cold water. Thioglycolic acid solution $(0.1 \mathrm{ml})$ was added, and the content was mixed. The tubes ware kept in the dark for $3 \mathrm{~h}$. The absorbance was measured at both $400 \mathrm{~nm}$ and $430 \mathrm{~nm}$ against the blank.

\subsection{Adsorption measurements}

The second step was to determine the curve for broth. $1 \mathrm{ml}$ of L-rhamnose standard was replaced by $1 \mathrm{ml}$ of broth solution $(0.5-30 \% \mathrm{v} / \mathrm{v})$.

The third step was to define relation for mixture of broth and hematite. To achieve this aim, eight broth solutions were made. $0.75-15.0 \mathrm{ml}$ of broth was transferred into the flasks and the volume was brought to $50 \mathrm{ml}$ with distilled water. Then solutions were added to the vessels containing $0.5 \mathrm{~g}$ of hematite. After $24 \mathrm{~h}$ of equilibration at the room temperature, samples were centrifuged $(1 \mathrm{~h}, 4200 \mathrm{rpm})$ and $1 \mathrm{ml}$ of each supernatant was taken to the further experiments, according to the procedure mentioned above.

\subsection{Sedimentation experiments}

Sedimentation measurements were performed using a Turbiscan LA $b$.(Formulaction, France). This apparatus allows the investigation of the stability versus height measurements. An optical head using a near infrared light $(850 \mathrm{~nm})$ vertically scans a height of $65 \mathrm{~mm}$ long, recording the transmitted and backscattered intensities. The sedimentation experiments were carried out at the constant $\mathrm{pH}$ and temperature $\left(20^{\circ} \mathrm{C}\right)$. The concentration of biosurfactant solution varied from 1.5 to $30 \% \mathrm{v} / \mathrm{v}$. Each sample consisted of $0.2 \mathrm{~g}$ of hematite and $20 \mathrm{ml}$ of suitable biosurfactant solution added into Turbiscan cell. After $24 \mathrm{~h}$ of equilibration the samples were investigated using Turbiscan Lab apparatus, which gave transmission and backscattering data over the length of the cell. The sedimentation rate was evaluated from the change of backscattering intensity with running time.

In order to determine data for pure rhamnolipid (from Jeneil Biosurfactant Co., USA), the same procedure, including adsorption isotherms and sedimentation experiments, was carried out. In this part, nine concentrations of rhamnolipid solutions were used (20-100 ppm). 
Fig. 1 Changes surface tension of broth and bacteria cell density during cultivation of Pseudomonas aeruginosa

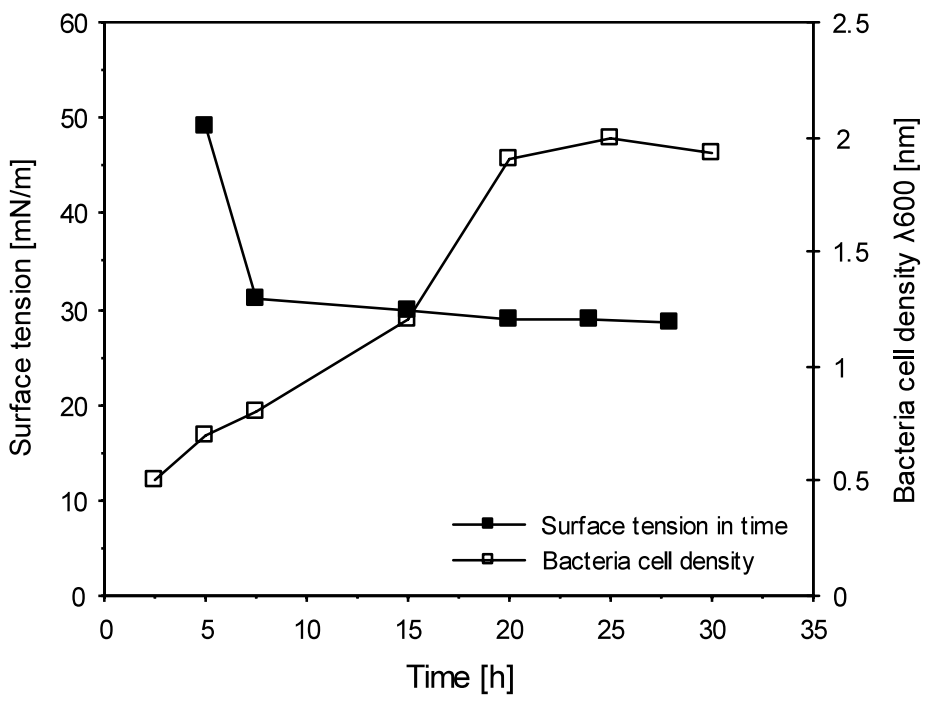

\subsection{Zeta-potential measurements}

The electrophoretic mobility of fine hematite particles ( $-40 \mu \mathrm{m}$ fraction) before and after interaction with the broth solutions were determined using Nicomp ${ }^{\mathrm{TM}} 380$ instrument (Santa Barbara, USA). $10^{-3} \mathrm{M} \mathrm{NaCl}$ solution was used as indifferent electrolyte. The zeta potential profiles for hematite were carried out in absence and presence of biosurfactant (broth solution).

\subsection{Microflotation procedure}

The flotation of hematite samples was carried out using a modified Hallimond tube. An amount of $1.0 \mathrm{~g}$ of $+40-$ $125 \mu \mathrm{m}$ fraction of hematite was used in flotation experiments. Prior to flotation, the hematite sample was conditioned with pure rhamnolipid or the broth solution and the $\mathrm{pH}$ was adjusted. The bioreagent was conditioned onto the mineral suspension for $30 \mathrm{~min}$. The suspension was transferred to the Hallimond tube and floated. The flotation recovery was calculated as the ratio of floated and unfloated mineral particles.

\subsection{Surface tension measurement}

The surface tension of the crude fermentation medium was measured using Du Nouy ring analysis system (Krüss K-11). The surface tension measurements were carried out at room temperature $20^{\circ} \mathrm{C}$. All of the measurements were repeated five times and their average values were used.

\section{Results and discussion}

The surface tension of the culture supernatant of Pseudomonas aeruginosa was measured as a function of cultivation time. Also, the microbial growth was conducted by measuring the turbidity of the culture medium in order to determine the change in the bacteria cell density. As shown in Fig. 1, the highest bacterial cell density appears at cultivation time of $20 \mathrm{~h}$. The highest of surface tension reduction of the culture media was achieved for $16 \mathrm{~h}$. Under the studied conditions, the log phase occurred, and ranged from 15 to $25 \mathrm{~h}$. In this period, the surface tension of the culture medium was strongly reduced.

The biosurfactant produced by Pseudomonas aeruginosa is rhamnolipid. The concentration of biosurfactant was measured by reverse phase HPLC with a Techsphere $5 \mu \mathrm{m}$ column (Lin et al. 1998).

Although the adsorption of ionic surfactants on charged solid surfaces has been the topic of many scientific investigations, the biosurfactant adsorption has been investigated less frequently (Hong et al. 1996; Shashikala and Raichur 2002). The amphiphilic nature of biosurfactants makes them adsorb readily to the solid-liquid interface. The adsorption of biosurfactans from the broth solution onto hematite particles is shown in Fig. 2. This adsorption experiments were realized at constant $\mathrm{pH}(\mathrm{pH}=7.3)$. As observed in Fig. 2, the adsorption increases systematically at the low concentration range $(12 \mathrm{ppm})$. Above this concentration the experimental isotherm is practically linear. Finally, it can be observed in the figure that the saturation of the adsorption is reached at the concentration range of $60 \mathrm{ppm}$. The shape of adsorption isotherm perhaps is related to the solid-surfactant interaction. The adsorption plateau was reached at $21 \mathrm{mg} / \mathrm{m}^{2}$ for $-40 \mu \mathrm{m}$ fraction and $2.8 \mathrm{mg} / \mathrm{m}^{2}$ for $+40-125 \mu \mathrm{m}$ fraction respectively. It should be noted, that the adsorption capacities of biosurfactant from culture media onto coarse particle fraction $(+40-125 \mu \mathrm{m})$ were relatively low. Rhamnolipids contain a hydrophilic head formed by one or two rhamnose molecules and a hydrophobic tail composed of one or two fatty acid chains. 
Fig. 2 The adsorption isotherm of biosurfactant from broth onto hematite
Fig. 3 The adsorption isotherm of pure rhamnolipid onto hematite
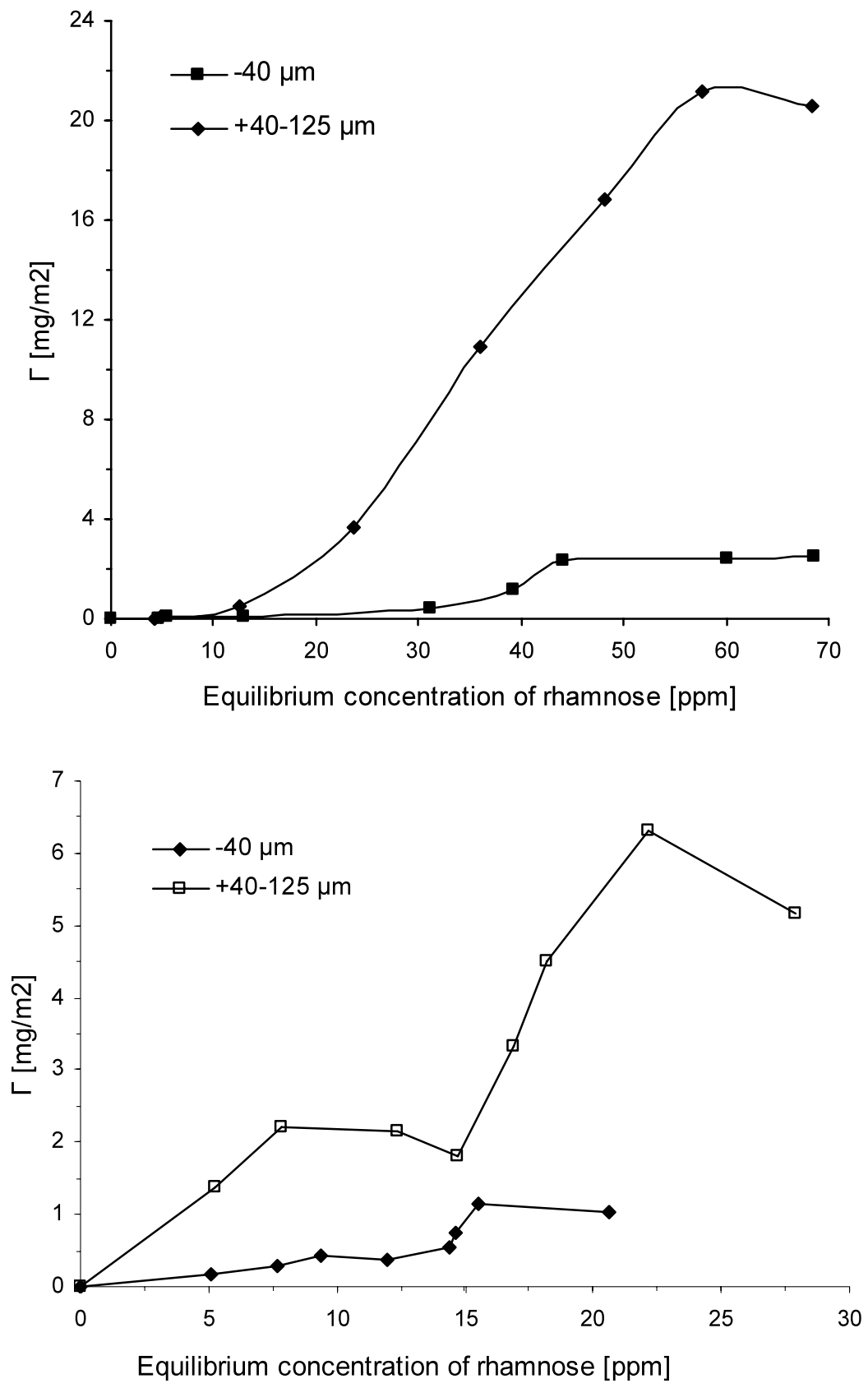

The observed differences between the adsorbed amounts of rhamnolipid (biosurfactant) are caused by the different specific surface areas of used the hematite fractions.

The adsorption behavior of pure rhamnolipid onto hematite $(-40 \mu \mathrm{m}$ fraction) suspension is presented in Fig. 3. Significant differences have been observed between the isotherms of pure rhamnolipid and rhamnolipid obtained from bacterial broth. For pure rhamnolipid isotherms show an increase in the vicinity of $15 \mathrm{ppm}$. The surface saturation of pure rhamnose was $1.2 \mathrm{mg} / \mathrm{m}^{2}$ for $+40-125 \mu \mathrm{m}$ fraction and approximately $6 \mathrm{mg} / \mathrm{m}^{2}$ for $-40 \mu \mathrm{m}$ fraction. These values were lower than for rhamnolipid obtained from broth.
These differences suggested that in case of rhamnolipid adsorbed from culture solution, the biopolymer-biosurfactant coadsorption can be observed.

However, the potential interference from compounds presented in culture broth has not examined. The adsorption of both surfactant and polymers is strongly influenced by the molecular structure. In case of the crude fermentation medium used for the mineral surface modification, this problem is significant.

This suggestion can be supported by the stability of hematite water suspension in the presence of broth and pure rhamnolipid. The effect of the biosurfactant addition on the 
stability of hematite is shown in Fig. 4, which presents the backscattering value BS (\%) for certain time (50 min) for each concentration. The difference between fermentation medium and pure rhamnolipid suspensions was observed especially at the low biosurfactant addition. The hematite suspension shows a tendency to flocculation with increasing broth concentration.

Surprisingly, when pure rhamnolipid was added, the strong flocculation was observed at a low concentration of reagent (at $7 \mathrm{ppm}$ ). Then the hematite suspension becomes more stable with increasing rhamnolipid concentration. Therefore, it can be considered that the hematite particles in pure rhamnolipid solution are sterically stabilized by the thick layer of biosurfactant. The broth is a mixture of metabolic products which contains some macromolecules such as polysaccharides and proteins. The adsorption

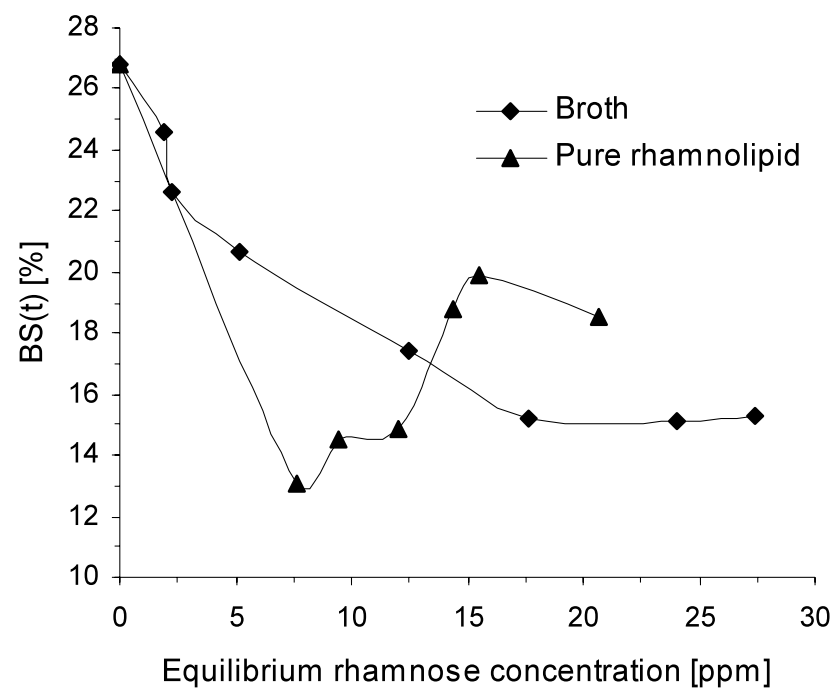

Fig. 4 Stability of mineral suspensions (hematite $-40 \mu \mathrm{m}$ ) with broth and pure rhamnolipid (BS-backscattering signal) of these macromolecules onto hematite surface can cause a permanent flocculation of mineral suspension.

Electrokinetic behavior of hematite before and after interaction with the broth is illustrated in Fig. 5. Before interacting with the broth, the IEP of hematite corresponded to $\mathrm{pH}$ value 5.8. After the broth interaction, the surface properties of mineral have changed. The $\mathrm{pH}$ of IEP has shifted towards higher $\mathrm{pH}$.

The shifts of measured zeta potential for hematite after interaction with the metabolite solution (broth) were similar to those observed in the presence of bacteria cells earlier (Deo and Naratajan 1997).

Similarly, no significant changes in the zeta potential were observed for hematite after interaction with Escherichia coli cells (Farahat et al. 2009).

Both flocculation and flotation studies were carried out to establish the selective separation of minerals after interaction with bioproducts (Patra and Natrajan 2003, 2004). Figures 6 and 7 show the effect of the reagent concentration on the rate of the hematite flotation.

Significant increase in flotation recovery of hematite was observed for small amount (20 ppm) of pure rhamnolipid. The recovery of hematite was found to be $100 \%$ for $20 \mathrm{~min}$ (Fig. 6). Similar flotation tests were carried out after the interaction with broth solution. The hematite recovery in this case was at the vicinity $45 \%$ (Fig. 7).

The obtained results can be attributed to the fact that broth contained polysaccharides, proteins and organic acids which make the surface of hematite more hydrophilic. For instance, polysaccharides containing $\mathrm{COO}^{-}$and $\mathrm{OH}^{-}$ groups can influence metal (iron) cation binding. Interaction and complex formation between iron and polysaccharides could occur what could be another reason behind the polysaccharides adsorption onto the hematite surface. The depressant action of the carbohydrates on the hematite flotation was observed (Pavlovic and Brandao 2003).
Fig. 5 Effect of broth concentration on the zeta potential of hematite $(-40 \mu \mathrm{m}$ fraction)

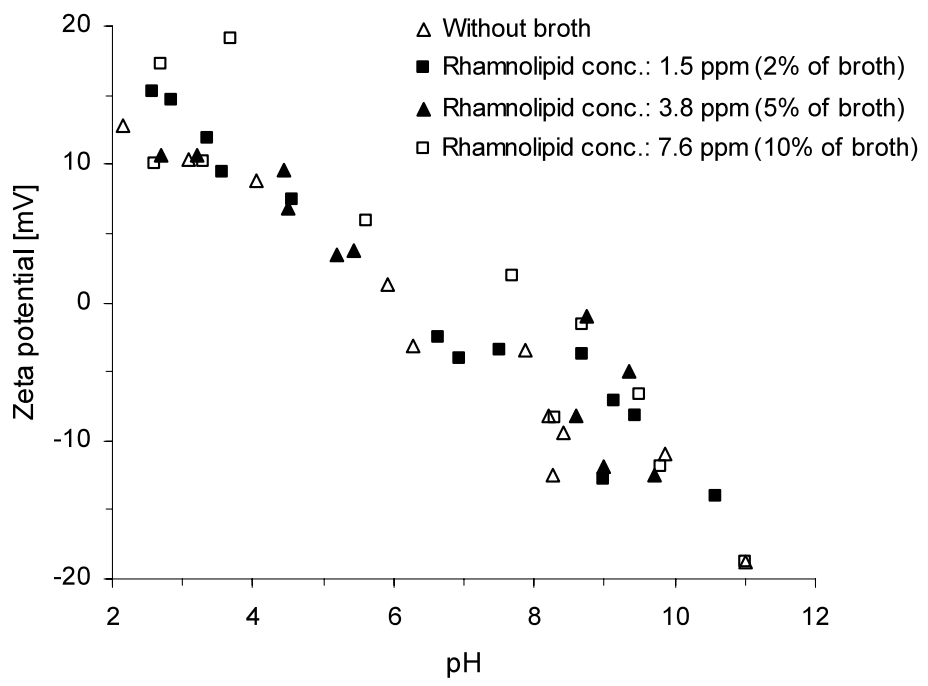


Fig. 6 Flotation of hematite particles with pure rhamnolipid as a collector

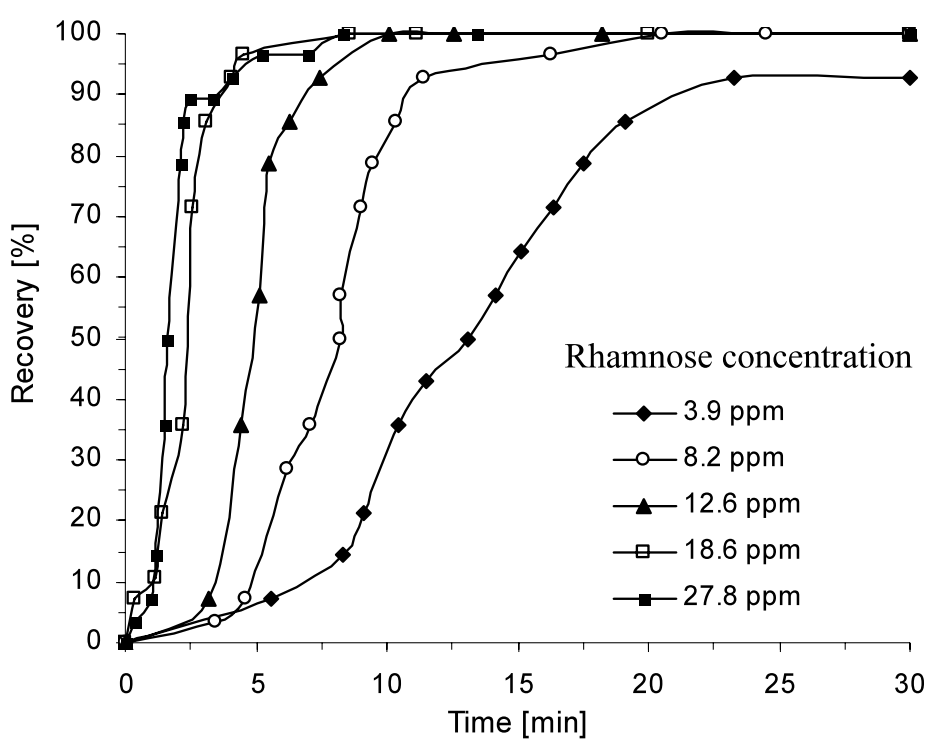

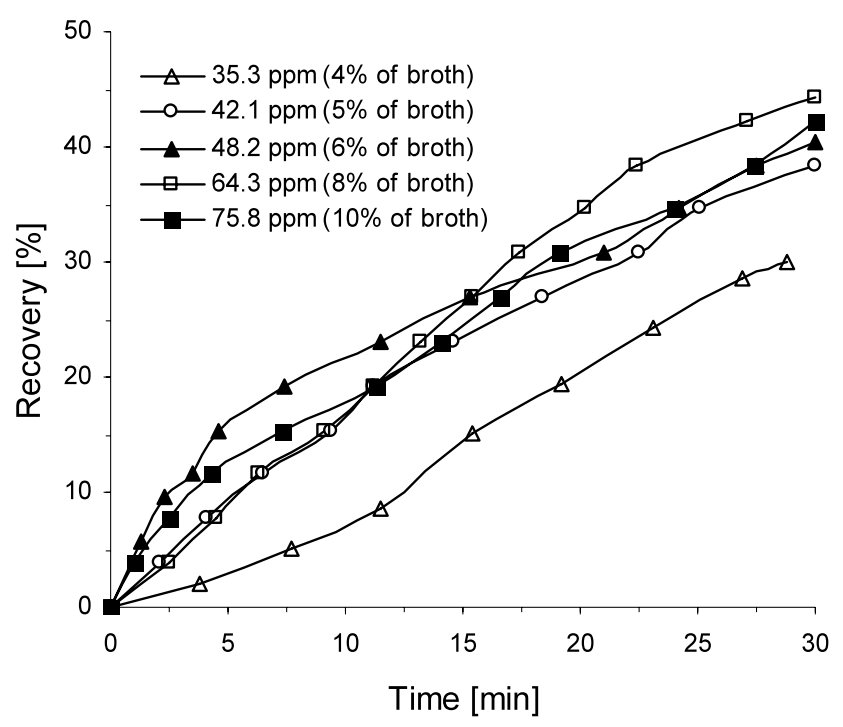

Fig. 7 Flotation of hematite particles with broth as a collector

\section{Conclusion}

In the present study, the effect of broth and pure rhamnolipid on the adsorption behavior of hematite particles has been investigated. The surface modification of hematite by pure surfactant and broth has shown different results. The observed stability properties of hematite suspension at higher concentration of pure rhamnolipid can be explained by the steric hindrance mechanism. If the surface coverage is small, the flocculation can be observed. It was also found that the effect of broth on dispersibility of hematite suspension should be considered as a flocculation by biopolymers. The adsorption data are in accordance with the zeta potential evaluation. Flotability of hematite particles was examined in the presence of pure rhamnolipid and broth solution. It was ob- served that hematite flotation was significantly depressed by broth. This behavior would suggest a better affinity of organic metabolites from broth onto the hematite surface.

Open Access This article is distributed under the terms of the Creative Commons Attribution Noncommercial License which permits any noncommercial use, distribution, and reproduction in any medium, provided the original author(s) and source are credited.

\section{References}

Banat, L.M., Makkar, R.S., Cameotra, S.S.: Potential commercial applications of microbial surfactants. Appl. Microbiol. Biotechnol. 53, 495-508 (2000)

Bordoloi, K.N., Konwar, K.B.: Microbial surfactant-enhanced mineral oil recovery under laboratory conditions. Colloids Surf., B Biointerfaces 63, 73-82 (2008)

Botero, C.E.A., Torem, L.M., de Mesquita, S.M.L.: Surface chemistry fundamentals of biosorption of Rhodococcus oparus and its effect in calcium and magnesium flotation. Miner. Eng. 21, 83-92 (2008)

Das, K., Mukherjee, A.K.: Characterization of biochemical properties and biological activities of biosurfactants produced by Pseudomonas aeruginosa mucoid and non-mucoid strains isolated from hydrocarbon-contained soil samples. Appl. Microbiol. Biotechnol. 69, 192-199 (2005)

Deo, N., Naratajan, A.K.: Interaction of Bacillus plymyxa with some oxide minerals with reference to mineral benefication and environmental control. Miner. Eng. 10(12), 1339-1354 (1997)

Farahat, M., Hirajima, T., Sasaki, K., Doi, K.: Adhesion of Escherichia coli onto quartz, hematite and corundum: extended DLVO theory and flotation behavior. Colloids Surf., B Biointerfaces 74, 140149 (2009)

George, S., Jayachandran, K.: Analysis of Rhanmnolipid biosurfactants produced through submerged fermentation using orange fruit peelings as a sole carbon source. Appl. Biochem. Biotechnol. 158, 694-705 (2009)

Hong, J.-J., Yang, S.-M., Lee, C.-H., Kim, M.: Adsorption of tricarboxylic acid biosurfactant derived from spiculisporic acid on titanium dioxide surface. Colloids Surf., B Biointerfaces 7, 221-233 (1996) 
Lin, S.-C., Lin, K.-G., Lo, C.-C., Lin, Y.M.: Enhanced biosurfactant production by a Bacillus licheniformis mutant. Enzyme Microb. Technol. 23, 267-273 (1998)

Mukherjee, S., Das, P., Sen, R.: Towards commercial production of microbial surfactants. Trends Biotechnol. 24, 509-515 (2006)

Patra, P., Natrajan, A.K.: Microbially-induced flocculation and flotation for pyrite separation from oxide gangue minerals. Miner. Eng. 16, 965-973 (2003)

Patra, P., Natarajan, A.K.: Microbially induced flocculation and flotation for separation of chalcopyrite from quartz and calcite. Int. J. Miner. Process. 74, 143-155 (2004)

Patra, P., Natarajan, A.K.: Role of mineral specific bacteria proteins in selective flocculation and flotation. Int. J. Miner. Process. 88, 53-58 (2008)
Pavlovic, S., Brandao, G.R.P.: Adsorption of starch, amylase, amylopectin and glucose monomer and their effect on the flotation of hematite and quartz. Miner. Eng. 16, 1117-1122 (2003)

Rahman, M.S.K., Rahman, J.T., McClean, S., Marchant, R., Banat, M.I.: Rhamnolipid biosurfactant production by strains of Pseudomonas aeruginosa using low-cost raw materials. Biotechnol. Prog. 18, 1277-1281 (2002)

Shashikala, R.A., Raichur, M.A.: Role of interfacial phenomena in determining adsorption of Bacillus polymyxa onto hematite and quartz. Colloids Surf., B Biointerfaces 24, 11-20 (2002)

Sim, L., Ward, O.P., Li, Z.-Y.: Production and characterization of a biosurfactant isolated from Pseudomonas aeruginosa UW-1. J. Ind. Microbiol. Biotechnol. 19, 232-238 (1997) 